AVANT, Vol. XI, No. 2

ISSN: 2082-6710 avant.edu.pl/en

DOI: 10.26913/avant.2020.02.09

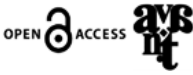

\title{
Context, Truth, and Objectivity: Essays on Radical Contextualism. A Book Review
}

Title: Context, Truth and Objectivity: Essays on Radical Contextualism

Series: Routledge Studies in Contemporary Philosophy. 1st Edition

Editors: Eduardo Marchesan, David Zapero

Publisher: Routledge

Release Date: 2018

Number of Pages: 260

Reviewed by

Manuela Teles

Universidade do Porto

Instituto de Filosofia

MLAG - Mind, Language, and Action Group

manuelateles@icloud.com

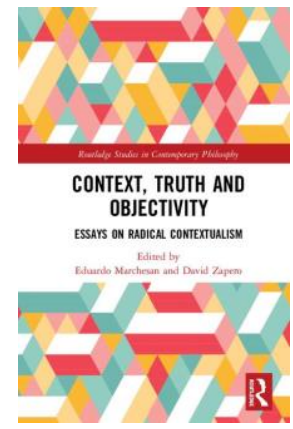

Received 13 March 2019; accepted 11 July 2019; published 22 February 2020

\begin{abstract}
What is radical contextualism? This review aims at using the contributions in this collection to provide answers to this question, considering further questions on contextualism, truth and language.
\end{abstract}

Keywords: contextualism; language; thought; truth; meaning

\section{Introduction}

What is radical contextualism? The title of this collection of essays provides some clues for finding an answer: whatever radical contextualism is, truth and objectivity are to be connected with it. This is an important clue if one considers the origins of contextualism within the philosophy of language. Contextualism may be introduced as a rejection of literalism, a view that meaning is purely linguistic. In contrast with literalism, which ascribes truth-conditions to sentences of natural languages, contextualism claims that ascriptions of truth can be accounted for only by considering the circumstances in which sentences are used. Assuming this is the core premise of contextualism, one further question emerges: what makes contextualism radical? 
According to David Zapero's introduction to this collection of essays, the root for radical contextualism is John Austin's claim that statements, and not propositions, are the genuine truthbearers. Zapero calls this Austin's Claim. Since other authors of the essays in this collection refer to the same claim by Austin, Zapero's nomenclature will be used throughout this review. Austin's Claim is the key to answer the questions just raised on contextualism and its radical stance. So, it demands more investigation. It is precisely this sort of investigation the essays in this collection provide. Each author offers a clarification or development of Austin's Claim and its place within contemporary philosophy, not only in the philosophy of language and the semantics, but also in other areas of philosophical investigation such as mind, perception, concepts and knowledge. To introduce Austin's Claim and its further imports, this review will analyze each essay in the collection changing its order of appearance in Zapero and Eduardo Marchesan's edition. The aim is to make visible one issue about radical contextualism: its relation to the notion of representation or representational views of language and thought. As I hope to show, radical contextualism may be considered to be the result of an increasing movement to do away with representations in the explanation of meaning, objectivity and truth.

\section{Truth and meaning: the radicalization of contextualism}

Jocelyn Benoist's essay, "What is a Statement?", aims at exploring the import of what, following Zapero, I call Austin's Claim. To do so, Benoist goes through a set of difficulties that may appear when the bearing of truth shifts from propositions to statements. The difficulties are related to the notion of statement. The first difficulty Benoist finds is explicitly presented in Austin's writings: the claim that statements are both performances and logical constructions. How can this be, though? If statements are logical constructions, how are they different from propositions? And if they are performances, how can they be qualified as true? Austin's Claim depends, on the one hand, on a relevant difference between statements and propositions, and on the other hand, on an understanding of how performances can be true. Benoist proposes that this difference and this understanding are achievable, considering Austin's notions of truth and performances. For Austin, Benoist explains, truth is one kind of many fits between words and the world, and a performance is an act of a human agent. Statements are thusneither propositions expressed in sentences nor performances that cannot be true, but acts of human agents that aim at truth. To clear the way to a correct understanding of the notion of statement as Austin proposed, Benoist suggests a double-sided perspective. For Benoist, statements should be taken as aspect-switching, in the sense that they can be seen as both logical and actual. In this way, ordinary language philosophy does not do away with a logical notion of truth when analyzing language use. The double-sided perspective of statements is the departure point to understand what Benoist takes to be Austin's revolution: the shift from a contentview to an act-view account of truth-bearers. In the content-view, truth-bearers are the propositions expressed by the sentences in a statement. But in the act-view, truth-bearers are the statements themselves. Thus, Austin's revolution is the touchstone in the transition from a literalist to a contextualist approach to meaning. As Benoist states it, the act-view allows for the separation of meaning and truth-bearers - in a statement, there is the meaning of the complete sentence in use and there is the truth-bearing of the whole situation in which such a sentence 
is used. Benoist suggests that, for Austin, there is an aboutness of truth, that is, truth is only where something is said about something. After analyzing how Austin considers statements joining descriptive and demonstrative conventions, accounting for the sameness of statements, and introducing the notions of locutionary and illocutionary acts, Benoist uses the aspectswitching perspective to conclude that the import of Austin's Claim is that the meanings of words are not enough to hook them onto the world. Without this hook, there can be no truth or falsity, since the hook is only found in actual linguistic performances. Thus, he concludes, contextualism is an essential feature of Austin's relocation of truth from propositions to statements. Benoist's clarification of Austin's proposals presents us with a double-sided perspective on what statements are. From this perspective, statements are both actual and logical. This is different from the philosophy of language tradition, in which context is considered to analyze the meaning of sentences. Austin's notion of statement, as Benoist presents it, is what introduces in the analysis of ordinary language the radical element: the idea that truth is not a property of propositions or the sentences that express them, but a property of situations in which a sentence is in use.

This radical element is explored in François Recanati's "Meaning and Ostension" considering Hilary Putnam. Recanati admits that Putnam is not part of the movements that put forward contextualism. Yet, he finds common ground in his proposals, mainly when Putnams's proposals are compared with Friedrich Waismann's and John Searle's thought-experiments. For Recanati, this common ground is the idea that truth-conditional content is 'essentially unstable and context-dependent'. This is what is at stake in Austin's Claim. According to Recanati, Waismann (cf. 1951, pp. 117-144) uses the notion of open texture to express the (contextualist) idea that truth-conditions are not assignable to ordinary sentences, for it is always possible to imagine a world where the state of affairs described as the truth-condition for a sentence is obtained while the sentence is not true. This shows that sentences are not sufficient to determine truth. Recanati appeals to Austin to explain that descriptions can only account for explicit features of reality, although implicit features also count when determining truth. There is no one description of a state of affairs that is the true one. This is taken into account by Searle, who offers a thought-experiment in which descriptions are not enough to determine whether different situation are the same (cf. 1978, pp. 207-224; 1980 pp. 221-232). For Recanati, Waismann and Searle's shared basic idea is present in Putnam's thought-experiments, which aim at showing that situations have features that are not available for language use. As Recanati notices, this is not yet a contextualist approach to meaning, but it can be worked out to become one. The result is the proper contextualist claim that non-linguistic features of the situations in which sentences are used are part of their truth-conditions.

Putnam is also an important influence in Charles Travis' essay "Their Work and Why They Do It". Travis is a central figure for radical contextualism for he introduced the notion of occasion-sensitiveness in the debates (cf. 2008). Occasion-sensitiveness is a reaction against what Travis calls the Ready-Made View. According to Travis, the Ready-Made View accepts that words 'are in the business of being true'. This is accountable in at least two ways. In what Travis calls the 'unvarnished' version of the Ready-Made View, words are in the business of being true for sentences inherit the truth-value of the thoughts they express. In what Travis calls the 'utopian socialist approach', words are in the business of being true for sentences express truth-conditions. Both versions are stances of Benoist's content-view. What is at stake 
for the Ready-Made View is that meaning and truth are a matter of language in itself. It is this idea that Travis wants to dismantle. For Travis, occasion-sensitiveness - the fact that the meaning of words is sensitive to the occasions of their use - is motivation enough to reject the Ready-Made View. Yet, he complains, this is not obvious for all. So, in his contribution, Travis wishes to present two motivations to reject the Ready-Made View: that we are Cartesian thinkers and that we are finite and fallible thinkers. It is to work on the idea that we are Cartesian thinkers that Travis appeals to Putnam. According to him, Putnam proposes that we are thinkers who are sensitive to reasons. Travis also appeals to John McDowell to elaborate this idea from Descartes. The idea is that, as thinkers, we can step back from what we are doing and reason about it. Travis' claim is that, as Cartesian thinkers, we are the ones who represent, not sentences or thoughts. As so, and this is where the second motive gets in: things may be different from how we represent them, i.e. we are not immune to error. Cartesian thinkers may think falsely, and they can express the wrong thought. More importantly, Cartesian thinkers can consider reasons for deciding which thought is being expressed in a given circumstance. The point is that, since we are Cartesian thinkers, the circumstances in which we use words to express thoughts differ according to the situations of use. So, the circumstances of an episode of thought-expression contribute to making the thought expressed recognizable. Thus, there is no special connection between one sentence and one thought.

Context-dependence shows that there has to be a distinction between making a thought recognizable, which is the task of words, and being accountable for being true, which is the 'business' of thoughts. For Travis, since the Ready-Made View does not account for this distinction, it has to be rejected. Travis' rejection of the Ready-Made View and proposal on the distinction between the role of words and the role of thoughts in language manifests Benoist's passage from the content-view to the act-view. This is developed by Travis presenting a model for occasion-sensitiveness in which to identify thoughts and to ascribe truth is to exercise a capacity that belongs exclusively to Cartesian thinkers. The exercise of such a capacity is both an engagement in language and the comprehension of what is being stated as true. Thus, to understand linguistic expressions is not to know what conditions have to be fulfilled for words to say something about the world, but rather to recognise that things are to be taken as being a certain way. Since this understanding is the actual exercise of a capacity and this exercise is context-dependent, the capacity at stake is theory-resistant. There is no theory that can provide a general account of how this capacity applies. The means for questioning whether what is encountered counts as being $\mathrm{F}$ comes with each novel candidate for being F. What Cartesian thinkers take to be (for instance) a pig, or gold under a specific circumstance is a matter of rational commitment.

\section{Language and beyond}

This notion of a rational commitment is what Eduardo Marchesan considers to be a divergence between Recanati and Travis in his essay "The Role of Intention in Truth". According to Marchesan, this divergence is the result of the criticisms each develop against Paul Grice's approach to context. Grice's proposals on the analysis of ordinary language are contextualist in that they appeal to conversational implicature. In Grice's model, the meaning of sentences is dependent on the interaction the speaker and hearer have with language and between themselves. 
Yet, as Krista Lawlor highlights in her essay, for Grice, there is still a 'conceptual content' in language use that is internally fixed. According to Marchesan, Grice's perspective on meaning and language is such that it creates an 'unbridgeable gap' between semantics - the meaning of words and linguistic expressions - and pragmatics - their use. For Marchesan, this gap is created by Grice's notion of what is said as propositional content. For him, the rejection that propositional content is sufficient to fix truth-conditions for utterances, and the gap it brings about between semantics and pragmatics, is achieved by two legacies of contemporary ordinary language philosophy: what he calls intentionalist contextualism and he calls conventionalist contextualism. Intentionalist contextualism is a legacy Marchesan builds as a radicalization of Grice's model. The need for this radicalization comes from the impossibility of applying Grice's implicature model to cases in which there is modulation. The problem is that, in cases of modulation, Grice's implicature model admits that speakers manipulate a literal meaning (propositional content) of which they may not be aware, or which can be unknowable to them so that hearers understand the inadequacy of a specific literal meaning of a certain situation while grasping the meaning of the utterance at stake. This reveals a fundamental tension between the two principles upon which Grice builds what is said: that it is a variety of non-natural meaning and that it is a literal meaning. For Marchesan, the aim of intentionalist contextualism's is to relieve this tension by abandoning the second principle. He points to Recanati (cf. 1989, pp. 295-329) and his availability principle as the core of intentionalist contextualism. With the availability principle, Recanati eliminates inferential processes on what is said and introduces radical indeterminacy so that if the hearer or speaker are unaware of the literal meaning of the sentence uttered, that is not what is being said. The idea is that the same propositional content might be mobilized to express different truth-conditions. What is said is thus differentiated from literal meaning, as Austin's Claim demands. However, this brings about one difficulty: given indeterminacy, how does the hearer establish the relevant information for the understanding of what is said in a given utterance? According to Marchesan, Recanati's answer is that speaker and hearer share not only a common code but also a psychological makeup. Thus, the speaker's meaning is a type of content recognized by a particular kind of psychological act, an 'intuition'. For the conventionalist contextualist, as Marchesan draws on Travis' proposals, this is not enough to assure that the speaker's meaning (what they intend to say) is understood by the hearer (what they recognize as what is intended to be said). Although Travis could share with Recanati the idea that some common psychological makeup is needed for meaning, he understands that an objective criterion has to be added. Conventionalist contextualism claims that in order for a speech act to have truth-conditions, it has to involve the expression of a Fregean thought. As it is well-known, Gottlob Frege conceived of thoughts as non-mental items, independent of psychological acts and nature. Frege's main motivation for what Dummett calls the extrusion of thoughts from the mind is his logicist project for arithmetic. For Frege, it is a condition for thoughts to be true or false that they are not subjective, but objective. Marchesan considers that, referring to Frege, Travis recovers the notion of convention as used by Austin, in which it is an 'objectivity-fostering factor'. So, in Travis' model for the analysis of ordinary language, there is no place for the speaker's meaning. For the conventionalist contextualist, fixation of reference and understanding have to be separated. Only by disentangling them can truth be part of the picture. This disentanglement, Marchesan proposes, overthrows Grice's first principle which states that what is said is operated by non-natural meaning. So, in 
Marchesan's perspective, there are two strands of radical contextualism, but only conventionalist contextualism is radical enough to overcome Gricean contextualism, and the gap between semantics and pragmatics it involves.

In her essay "Is Seeing Judging? Radical Contextualism and the Problem of Perception", Sofia Miguens approaches Travis' radical contextualism in the context of contemporary debates over the philosophy of perception. At the center of these debates is the question whether perception is, or is not, representational. As it is well known, Travis has a prominent role in defending an anti-representationalist account of perception. Miguens proposes that this is the result of his commitment to radical contextualism. This commitment is what Miguens believes to be at the core of Travis' disagreements with McDowell. In contrast with Travis, McDowell defends a representationalist account of perception. Miguens suggests that the disagreement between both has to do with the philosophical heritage each of them draws on: while McDowell develops his representationalist account from Immanuel Kant's conception of mind, Travis develops his anti-representationalist account on the basis of Frege's conception of thought. To make her point, Miguens begins with an analysis of McDowell's criticisms of Tyler Burge's reaction to his version of disjunctivism. According to Miguens, Burge defines disjunctivism as a question on mental states with specific representations, while McDowell defends it as a matter of appearances and how they represent the world. McDowell's disjunctivism, Miguens claims, is grounded in epistemology, while Burge's is based on psychology. This is what, from her perspective, is at the heart of the clash between them. For Burge, perception involves sub-personal and personal states with psychological contents, so both levels are representational. For McDowell, although perception may involve processes at sub-personal states, perceptual representations are appearances (of the world) to a subject, so they are present only at the personal level. Travis would agree that perception occurs at a personal level and appearances are something of the world. His issue with McDowell, Miguens proposes, concerns the very idea that appearances are representations. To introduce the dispute between Travis and McDowell, Miguens considers Daniel Dennett's positions on the matter. For Dennett, she explains, the subject of a perceptual experience cannot decide between appearances ('seemings', for Dennett) and reality: seeing is judging that things are a certain way. But this is something McDowell tries to eliminate. Based on an interpretation of Kant's Anschauung, McDowell proposes that perceptual experiences have intuitional content that is representational but not propositional. Drawing a parallel with language, this position about perception is not so distant from that of Marchesan's intentionalist contextualism. As Miguens highlights, McDowell claims that conceptual capacities are exercised already at the personal level of perception, but this is what Travis's commitments to radical contextualism reject. While for McDowell things appear as being thus and so in perception but become explicit to the subject as the content of their perceptual experience only in judgements, for Travis it is only in judgements that things appear as thus and so. In Travis' account, as is emphasized in his contribution to this collection, the relation between minds and the world is an achievement of a thinker, not a task of representations. So, for there to be representation, there has to be speech acts and an environment: there are no conceptual capacities prior to the doings of an agent in an environment. This idea is what, for Miguens, is the core of Travis' radical contextualist approach to representation. In Travis' account, the only representer is a thinker on an occasion: neither sub-personal states 
nor perceptions or thoughts represent. Thinkers do, and this anti-representationalist account is the effect Travis' radical contextualism's has on his philosophy of perception.

David Zapero's essay, "Externalism and Context-Sensitivity”, considers the implications of Travis' radical contextualism (and anti-representationalism) for the philosophy of mind. Departing from the apparent perplexity caused by the possibility of thinking something false about an object, Zapero considers the scenario in which a concept is used to think about something that does not fall under it. This scenario is used by Zapero to introduce the Travisian idea that thinking is a world-involving activity: to represent that things are thus and so is to think that something falls under a concept, and to do this one has to consider how the world is. In Zapero's view, this trivial idea raises an important question about radical contextualism: how do we decide when something falls under a concept? One traditional answer considered by Zapero is the one offered by Frege according to which the group of objects that fall, and do not fall, under a concept is part of the concept's definition. As we have seen, Travis makes a departure from this definitional answer. His claim is that the decision on what falls under a concept must be made on a case-by-case basis. Following on Travis' proposal, Zapero rejects the traditional account for it assumes that the world has no role in deciding what falls under a concept. When applied to thoughts, the traditional view accepts that the world plays a role in deciding whether a thought is true (or false) but not in deciding when it counts as being so. As Zapero puts it, and Marchesan distinguishes, Travis' radical contextualism is conventionalist in that the decision about whether something falls under a certain concept is case specific. There is no one general theory for all the cases. So, what counts as something falling under a certain concept is, as Travis proposes, theory-resistant. Something falls under a concept when it is recognized as such in a concrete situation by a certain kind of thinker, namely a Cartesian thinker. Following Travis, Zapero proposes that conceptual capacities are just recognitional. That is, there is no exercise of conceptual capacities where there is no object to recognize as being that way. According to Zapero, this thesis grounds Travis' rejection that thoughts are structured, in that being about an object or a way for something to be picks out one particular thought. To be about an object or to be about being a certain way is not sufficient to pick out one particular thought because a concept can amount to different things. There are multiple thoughts to the effect that $a$ is $F$. The point is that the two capacities necessary to think something as being a certain way (identify $a$ and think something as being $F$ ) are not sufficient to determine the truth-value of the thought. What determines if something is a certain way ( $a$ is $F$ ), is the recognition of the facts, on a given occasion, and how they are presented in the thought. Concepts and thoughts are thus not fixed entities that one can express correctly or incorrectly. This leads to Zapero's conclusion that the possibility of misapplication of concepts does not lead to pseudo-concepts or nonexistent objects: there are no ways for things to be independent of things being. Thus, the perplexity generated by false singular thoughts does not take place from a radical contextualist perspective. 


\section{Skepticism and knowledge claims}

Another perplexity that radical contextualism may contribute to avoid is the one created by the so-called argument from ignorance, which can be briefly introduced like this:

1. I know I have hands.

2. If I know I have hands, then I know I am not a brain in a vat.

3. I do not know I am not a brain in a vat.

From the argument from ignorance, the skeptic considers that the conclusion to be drawn would be:

I do not know I have hands.

In her contribution to this collection, "Ordinary Language Philosophy needs Situation Semantics (Or, Why Grice needs Austin)", Krista Lawlor claims that the skeptic builds this argument as a paradox, considering that the three premises are all taken to be true by common sense yet cannot all be true together. However, she claims, Austin's, but not Grice's, analysis of ordinary language provides a response to the skeptic, and thus to the argument from ignorance. Lawlor's point is that Austin offers two supports for dismantling the argument from ignorance. These supports are situation semantics and its corollary condition for knowledge claims. According to Lawlor, Grice's analysis of ordinary language is based on two principles that allow skepticism to thrive.

In Lawlor's view, Grice and Austin share the approach to philosophy of ordinary language as a conceptual analysis. For Grice, such a conceptual analysis enables explicit understanding of what language users know implicitly. In his approach, philosophy of ordinary language is not only about linguistic meaning but also about the knowledge involved in language use. Lawlor takes this picture of ordinary language philosophy to be broadly shared by Austin. She considers that both Austin and Grice assume that a conceptual analysis of language use reveals 'commonsense commitments'. What distinguishes Austin and Grice's approaches to ordinary language is the nature of these commitments. Whereas for Grice ordinary language reveals a common structure that is the content of language as such, for Austin the revelation is that ordinary commitments are taken "as used on particular occasions to talk about particular situations" (see p. 37). According to Lawlor, for Austin, the function of linguistic meaning in natural language is not to determine specific truth conditions but to provide a constraint of interpretation when language is in use. So, the function of a meaningful expression is to establish truth conditions for particular utterances in the specific situation of use. Austin's situations semantics thus involves what Lawlor considers to be a conceptual content: a shared knowledge of what linguistic expressions mean in each situation in which they are used. The truth and meaning of an utterance of knowledge depends then on the situation talked about and the relevant alternatives in the situation of utterance. That is, knowledge claims are context-dependent. Thus, where Grice cannot avoid the skeptical paradox, for he takes language to have a fixed structured meaning that is independent of use, Austin can reply to it considering that whereas 1. and 3. of the argument from ignorance are taken to be true when uttered, 2. may be not. Since knowledge claims are context-dependent, it is only in some circumstances that I know that I am not a brain in a vat if I know that I have hands. The result, Lawlor concludes, 
is that the skeptical paradox does not obtain within Austinian situation semantics: it is not always the case that the three premises involved in the argument from ignorance are taken to be true. This also shows her more general point: that the only way for ordinary language philosophy to defend common sense against skepticism is to adopt Austin's situation semantics and reject Grice's idea that what is said determines truth conditions.

Differing with Lawlor, in his essay "Beyond Unnatural Doubts: Lessons from Wittgenstein", Michael Williams considers that Austinian situation semantics motivates the rejection of 1. Aiming to clarify some points from his earlier Unnatural Doubts (1996), Williams wishes to build a response to what he considers Cartesian skepticism to be. According to him, René Descartes challenged epistemological reasoning from skeptical hypotheses to the possibility that most of our beliefs about the external world are false. This is a specification of the argument from ignorance and the skeptical paradox. Cartesian skepticism differs from what Williams calls Agrippan skepticism in that it is not based on the threat of infinite regress but on the idea that knowledge about the external world is grounded in experiential knowledge. So, the reasoning is, where there is no experiential knowledge there cannot be knowledge about the external world. The problem Williams finds in the traditional responses to Cartesian skepticism is that they share the same ground. For epistemic realism, as Williams calls it, as for Cartesian skepticism, knowledge is an object of theory that can be evaluated as a whole. So, if Lawlor's Austinian answer to the skeptical paradox is a stance of epistemic realism, it is also a target for Williams. In Unnatural Doubts, Williams rejected Cartesian skepticism by defending knowledge as contextual, not theoretical, so that epistemic realism is false. His proposal in the present essay is that, although a general theory of knowledge cannot be considered, one can build an epistemic contextualism. In an epistemic contextualist framework, to know is a matter of being placed in the world with the relevant recognitional capacities or background knowledge. To build epistemic contextualism, Williams draws on Ludwig Wittgenstein and Austin. So far, we have been considering Austin's proposals. Now, we will look more closely at Williams' reading of Wittgenstein. According to Williams, one contextualist tradition of Wittgenstein's interpretation is attributor contextualism, which assumes that Wittgenstein argues that there are no basic certainties, and thus motivates skepticism. Williams rejects this view and proposes instead that Wittgenstein's passages are not about a general skepticism but about scientific investigation as a systematic research. Williams claims that what Wittgenstein is defending in those passages is that systematic investigations, such as those advanced by science, depend on a background of everyday, common sense, knowledge: basic known certainties. These basic known certainties are the key to an epistemic contextualist response to Cartesian skepticism. In Williams' Wittgensteinian view, basic certainties are like axes that impose a limitation to where our knowledge claims move to. Basic certainties depend on our ordinary practices for epistemic assessment and thus vary with the circumstances. So, although basic certainties can be proven to be false, it makes no sense to doubt them. Williams' epistemic contextualist reply to Cartesian skepticism is thus that skeptical scenarios do not make sense. They are, as Williams puts it, 'fairy tales'. The argument from ignorance is indeed a skeptical scenario. So, if Williams is right, it is a fairy tale. Williams arrives at the following conclusion: to claim that objective certainty is context-dependent is not to claim that circumstances are some kind of Cartesian skeptical scenario; it is instead to claim that 
circumstances shape our basic certainties. Thus, the problem with the argument from ignorance is 1 , since it presupposes that a proposition can be identified by its content and that this is a proposition that cannot be doubted. Both assumptions are wrong, according to Williams. There are circumstances in which it is true to say that one has hands, and circumstances in which it is not.

In his essay, "Contextualism and the Twilight of Representationalism", Avner Baz offers an alternative to representationalist radical contextualism, , considering a response to Cartesian skepticism that does not appeal to representations. Baz rejects the radical contextualist account so far considered, for it is grounded on a representationalist approach to language that he considers is not in accordance with either Wittgenstein or Austin's proposals. In Baz's view, this approach, which he attributes to Travis, takes language's first and most important role to be that of being a vehicle of communication and considers that representing something as true or false is the basic relation of minds to the world. From Baz's perspective, Wittgenstein and Austin's point is the rejection of semantics as the only relation between minds and world. In Baz's reading, Wittgenstein proposed meaning to be a common ground for intersubjective differences and Austin's aim is to show that not all performative utterances are assessable as true or false. Nonetheless, contemporary radical contextualists, such as Travis, assume that truth is connected to thoughts and thoughts have to be expressed in order to achieve truth. The representationalist approach sees language as the only vehicle to achieve truth, which is, for Baz, contrary to both Wittgenstein and Austin's purposes. Baz's alternative to representationalism refers to Wittgenstein and Austin, considering that knowledge is to be accounted for from a personal and ethical perspective. Thus, knowledge claims are to take into account not only the worldly conditions in which they are uttered but also the interpersonal commitments that guide their acceptance or rejection. An Austinian response to skeptical challenges, then, does not involve an analysis of the workings of the linguist term 'to know' in discourse, but an analysis of the already world-involving speech acts. For Baz, the core contextualist idea is thus that, beneath the world we talk about, there is the world in which we are and to which we are responsive. From here, Baz defends that contextualism can, and should, address skeptical challenges, assuming that linguistic terms that are sensitive to context have context-sensitive references and thus there is no such a thing as a Kantian 'world in itself'. Baz's alternative to Travis' 'representationalist' radical contextualism is a somewhat phenomenological view in which judgement is not the foundational relation to the world. Instead, from this perspective, the world is already shared before we position ourselves in it by means of language. Thus, securing an environment is not an achievement of thought or judgement (or cognition) provided by language. It is rather the condition for thought and judgement (or cognition).

\section{Conclusion}

In the context of Baz's attack at representationalism, one may ask about the relation between radical contextualism and representation. In fact, the essays gathered in this collection may invite us to see radical contextualism as an increasing movement towards the elimination of a notion of representation in an analysis of meaning. The first step to this elimination is Austin's Claim. The readings and developments of Austin's Claim provided in the essays in 
this collection offer different ways for such an elimination. Benoist's aspect-switching perspective of statements makes manifest the non-representational character of statements. Recanati calls attention to the insufficiency of descriptions, as linguistic representations, to bear truth. For Travis, representation can, and should, be excluded from language for it is a matter for thinkers. Marchesan, Miguens and Zapero show that radical contextualism is a point of departure to detach language, experiences and concepts from a representationalist account. Finally, Lawlor and Williams point to different directions in order to establish a position in epistemology from radical contextualism. Their different responses to the argument from ignorance, considering the skeptical paradox and Cartesian skepticism, together with Baz's alternative, introduce the possibility of considering knowledge from a radical contextualist standpoint, in which there are no representations to compare with the world.

This collection of essays provides an insight into the roots and developments of radical contextualism as Austin's legacy within ordinary language philosophy that has earlier roots in Wittgenstein, and as a reaction to the later developments of this legacy, namely by Grice. The essays also provide a map of the different courses this shift may lead to. Some of them concern ordinary language philosophy and how it should consider language use, thought and truth; others consider the effects this shift can have in other philosophical areas. Overall, these essays not only answer the initial questions of this review as they call for future inquiries. One interesting inquiry is into the contextualist flair that may be found in authors such as Frege and Putnam, but also Waismann and Reichenberg. A more interesting one, though, may be that concerning the role of representation in a philosophical analysis of language, and the implications it may have for the investigation of mind, knowledge and the world. It is here that objectivity and truth may have a crucial role.

\section{References}

Austin, J. L. (1962a). How to Do Things with Words: The William James Lectures. Delivered at Harvard University in 1955. Oxford: Clarendon, 1962.

Austin, J. L. (1962b). Sense and Sensibilia. Edited by G. J. Warnock. 2nd ed. Oxford: Oxford University Press.

Austin, J. L. (1979). Philosophical Papers. Oxford: Clarendon.

Dummett, M. (1993). Origins of Analytical Philosophy. Cambridge, MA: Harvard University Press.

Frege, G. (1918). "Der Gedanke”. Beiträge zur Philosophie des deutschen Idealismus 2. In Logische Untersuchungen (pp. 58-77). Hrsg. Günther Patzig, Göttingen, Vandenhoeck und Ruprecht, 1993. English translation: M. Beaney. (1997). The Frege Reader (pp. 325-345). London, Blackwell,.

Grice, P. (1989). Studies in the Way of Words. Cambridge, MA: Harvard University Press.

McDowell, J. (1994a). Mind and World. Cambridge, MA: Harvard University Press.

McDowell, J. (1994b). The Content of Perceptual Experience. Philosophical Quarterly, 44(175), 190-205. Reprinted in a slightly different form in J. McDowell, (1998). Mind, Value and Reality (341-358). Cambridge, MA: Harvard University Press,. 
Putnam, H. (1962). It Ain't Necessarily So. The Journal of Philosophy, 59(22), 658.

Putnam, H. (1975). The Meaning of 'Meaning'. In H. Putnam. Philosophical Papers, vol. 2: Mind, Language and Reality (215-271). Cambridge: Cambridge University Press.

Putnam, H. (1988). Representation and Reality. Cambridge, MA: MIT Press.

Recanati, F. (1989). The Pragmatics of What is Said. Mind \& Language, 4(4), 295-329.

Recanati, F. (2004). Literal Meaning. Cambridge: Cambridge University Press.

Searle, J. (1978). Literal Meaning. Erkenntnis, 13, 207-224.

Searle, J. (1980). The Background of Meaning. In J. Searle, F. Kiefer and M. Bierwisch (eds.), Speech Act Theory and Pragmatics (pp. 221-232), Dordrecht: Reidel.

Travis, Ch. (2008). Occasion-Sensitivity: Selected Essays. Oxford: Oxford University Press.

Waismann, F. (1951). Verifiability. In A. Flew, (ed.), Logic and Language, 1st series (pp. 117144). Oxford: Blackwell.

Williams, M. (1996). Unnatural Doubts: Epistemological Realism and the Basis of Skepticism. Princeton, NJ: Princeton University Press.

Wittgenstein, L. (1969). On Certainty. Edited by G. E. M. Anscombe and G. H. von Wright, translated by Denis Paul and G. E. M. Anscombe. New York and Evanston: Harper.

Wittgenstein, L. (2009). Philosophical Investigations. German text with English translation by G E. M. Anscombe, P. M. S. Hacker and Joachim Schulte. Revised 4th edition by P. M. S. Hacker and Joachim Schulte. Chichester: Wiley-Blackwell.

The editorial and publishing process of this publication has been financed by the Ministry of Science and Higher Education from the funds for the dissemination of research (DUN) within the framework of publishing activity, contract no. 711/P-DUN/2019, period of implementation: the years 2019-2020. 